\title{
THE EFFECT OF BLOWING AGENTS ON THE EFFECTIVENESS OF POLY(VINYL CHLORIDE) EXTRUSION
}

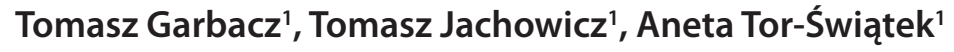 \\ 1 Lublin University of Technology, Mechanical Engineering Faculty, Department of Polymer Processing, \\ Nadbystrzycka 36, 20-618 Lublin, Poland, e-mail: t.garbacz@pollub.pl, t.jachowicz@pollub.pl, a.tor@pollub.pl
}

Received: 2016.08.15 Accepted: 2016.10.06 Published: 2016.12.01

\begin{abstract}
The cellular extrusion is a method for manufacturing profiles, bars, low density cellular coatings and other cellular products that have no hollow cavities on the surface and show minimal processing shrinkage, while their properties are similar to those of products produced by conventional extrusion. The paper deals with cellular extrusion of PVC. The investigation of the process was conducted using state-of-the-art endothermic and exothermic blowing agents that were dosed in up to $1.5 \%$ by weight. The experiments involved measuring output, energy consumption and energy efficiency of the process.
\end{abstract}

Keywords: cellular extrusion, effectiveness, poly(vinyl chloride), blowing agents.

\section{INTRODUCTION}

In cellular extrusion, thermoplastics are processed by blowing agents that can generally be divided into chemical and physical blowing agents $[4,7,17]$. Physical blowing agents include hydrocarbons, water, nitrogen and carbon dioxide. They are added in a liquid or gas state into the polymer melt and then mixed with nucleates, e.g. talc. In contrast, chemical blowing agents are added into granulated polymers as solids (powder or pellets) and fed into the plasticizing unit through gravimetric or volumetric feeders. The mixture of the polymer and blowing agent is then processed in the plasticizing unit and shaped using a standard tool (injection mold, head, etc.) $[3,5,13,15]$. As is the case with physical blowing agents, chemical blowing agents produce gas that is dissolved in the polymer $[9,12]$. The gas release reaction can be endothermic or exothermic $[7,9,15,18]$. When using chemical blowing agents, one should take into account the fact that their decomposition temperature must be exceeded in order to produce the required amount of gas. Cells produced thereby are filled with air or various gases, e.g. $\mathrm{CO}_{2}$ or $\mathrm{N}_{2}$ and later replaced with air due to diffusion $[8,14,18]$.

The effectiveness of polymer extrusion is significantly affected by phenomena that occur in the plasticizing unit. As demonstrated in the studies $[1,8,10,16]$, the processing conditions as well as design of the extruder's plasticizing unit are here of vital importance here; nonetheless, it must be observed that the above studies discuss heating, compression and conveyance of solid, and not cellular plastics. The problem of impact of the plasticizing unit, feed opening, barrel and extruder screw designs on the effectiveness of extrusion has been investigated in the studies $[6,11]$. However, these studies focus on the extrusion of solid plastics and, hence, do not offer any universal and comprehensive relationships or solutions that could also be applied to cellular extrusion.

One problem that is rarely discussed and still inadequately investigated concerns the effect of various blowing agents (exothermic, endothermic, pellets or microspheres) on the effectiveness of cellular extrusion. The results reported in the studies $[6,13,14,18]$ demonstrate that the chemical properties of the blowing agents facilitate the 
polymer flow in the plasticizing unit and extruder head. They do not determine, however, if the blowing agents have any impact on the effectiveness and efficiency of the extrusion process. Also, investigation of the extrusion process with regard to decomposition, number of cells, mechanical properties and structure of cellular extruded products made of HDPE/PP, PVC were conducted [9, 12, 18]. The studies about investigate the effectiveness of manufacturing cellular products are also significant $[2,14]$. Despite the numerous publications on extrusion including cellular extrusion, there is, in fact, lack of information on the effectiveness of extrusion performed using different blowing agents, the same starting parameters and a constant geometry extruder.

\section{EXPERIMENTAL}

The objective of this study is to determine in experimental tests the effect of blowing agent decomposition characteristics and its content in polymer on cellular extrusion and its effectiveness for plasticized poly(vinyl chloride). The process is defined by variations in the temperature and weight of the extrudate, while its effectiveness is defined by variations in the mass and volumetric flow rates of the polymer, power supplied to the extruder, power conveyed by the polymer and energy efficiency of the extrusion process.

\section{MATERIAL}

The materials used in the experiments included plasticized poly(vinyl chloride) (PVC) and three types of chemical blowing agents. The blowing agents applied in the experiments had the form of pellets and, as a result, they could be mechanically mixed with the polymer being processed. The tested material was PVC marketed under the trade name of Alfavinyl GMF/4-31TR, manufactured by Alfa PVC Sp. z o.o (Poland). According to the data provided by the manufacturer, this plastic contains $31 \%$ plasticizer (dioctyl phthalate) and lime-zinc stabilizer. Its density $\rho_{\left(23 \pm 2^{\circ} \mathrm{C}\right)}$ ranges from 1230 to $1400 \mathrm{~kg} / \mathrm{m}^{3}$, the mass flow rate $\mathrm{MFR}_{\left(150^{\circ} \mathrm{C} / 10.29 \mathrm{~kg}\right)}$ is between 4.3 and 4.6 $\mathrm{g} / 10 \mathrm{~min}$, the elongation at break amounts up to $300 \%$, the tensile strength at break is $\geq 21 \mathrm{MPa}$ and its Shore hardness A is equal to 80 . The recommended processing temperature of this material is between 120 and $190^{\circ} \mathrm{C}$.
In the experiments, various types of chemical blowing agents were used: Hydrocerol 530, manufactured by Clariant Masterbatches $\mathrm{GmbH}$, LyCell-F017 manufactured by Ly-TeC $\mathrm{GmbH}$, and Expancel 950 MB80 manufactured by Akzo Nobel. Hydrocerol 530 is an exothermic blowing agent with nucleating properties. It comes in a granular form, with the diameter of spherical grains ranging from 2.4 to $2.8 \mathrm{~mm}$. In order to obtain high foaming process efficiency, the processing temperature should range between $120-170^{\circ} \mathrm{C}$. The active substances in this blowing agent constitute a mixture of appropriately proportioned chemical compounds such as azodicarbonamide. LyCell-F017 is an endothermic blowing agent. It has the form of pellets with a diameter ranging from 1.2 to $1.8 \mathrm{~mm}$ and a length from 2.3 to $2.5 \mathrm{~mm}$. This blowing agent is a mixture of sodium acid carbonate and 2-hydroxypropane-tricarboxylic acid (citric acid). Expancel $950 \mathrm{MB} 80$ is a blowing agent that has the form of spherical thermoplastic polymer capsules (microspheres) that contain a hydrocarbon gas. This is an endothermic blowing agent. Expancel microspheres do not bond because the capsules retain their blocking properties, which prevents release of the constrained gas. Expancel $950 \mathrm{MB} 80$ is a mixture that contains $65 \%$ microspheres in the copolymer of ethylene and vinyl acetate (EVA). The decomposition products of the applied blowing agents mainly include carbon dioxide $\mathrm{CO}_{2}$, a small amount of water $\mathrm{H}_{2} \mathrm{O}$ and nitrogen $\mathrm{N}_{2}$. The process of modifying the polymer by the application of the blowing agents was performed in a laboratory of the Department of Polymer Processing at the Lublin University of Technology.

\section{RESEARCH METHODOLOGY}

The experimental tests were conducted on a laboratory technological line for profile extrusion, its main component being a single-screw extruder T32-25 (Figure 1). The extruder's plasticizing unit had four heating zones, the screw had an $\mathrm{L} / \mathrm{D}$ ratio of 25 and an outside diameter, $D$, of $32 \mathrm{~mm}$. The rotational speed of the extruder screw ranged from 0 to $120 \mathrm{rpm}$ and was adjusted continuously. The technological line also consisted of a head for profile extrusion. The head had a replaceable extruder die to enable extrusion of profiles with different sizes and shapes, both symmetric and asymmetric. Used for tape profile 

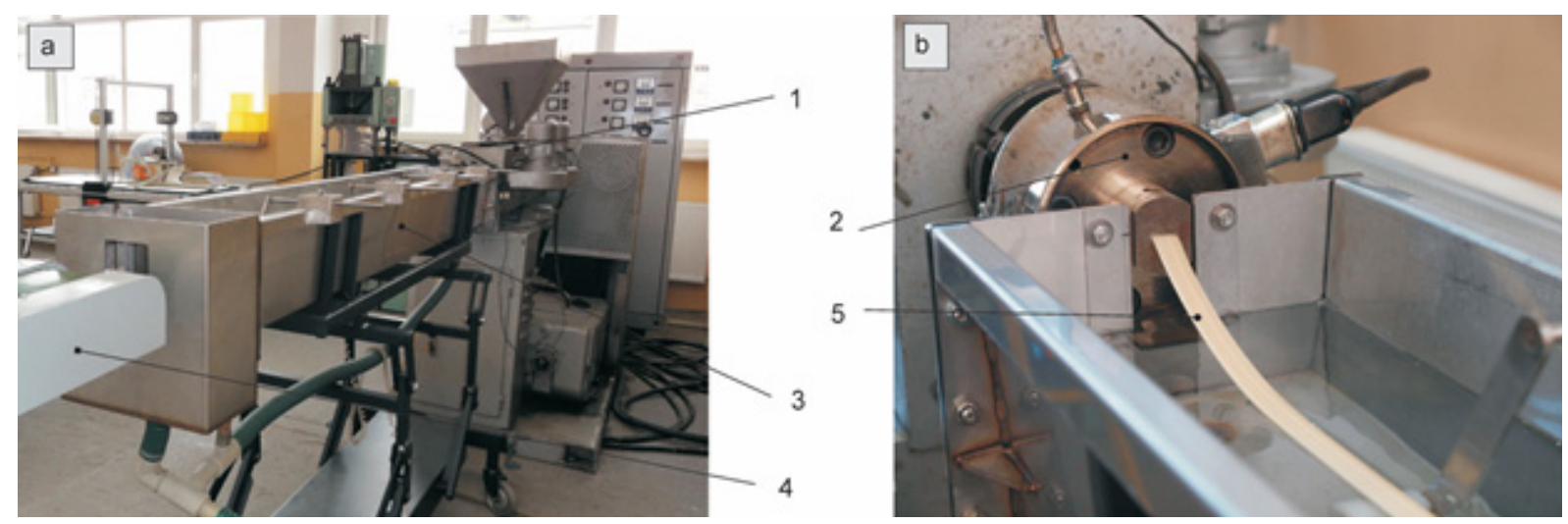

Fig. 1. View of technological line for cellular extrusion: (a) general view and (b) head with a die for tape producing, and with the tape produced: 1 - single screw extruder; 2 - extrusion head; 3 - cooling device; 4 - receiving device; 5 - extrudate

extrusion, the die had a width of $15.5 \mathrm{~mm}$ and a height of $2.0 \mathrm{~mm}$. The extruder head was made up of two heating zones and two corresponding ringshaped heaters mounted on the head body. The extrusion line also consisted of a cooling device that had a length of $1740 \mathrm{~mm}$, width of $220 \mathrm{~mm}$ and depth of $200 \mathrm{~mm}$. In the tests, we also used a belt haul-off; the belt had a width of $100 \mathrm{~mm}$ and a length of $2000 \mathrm{~mm}$.

The cellular extrusion process was run at the temperature of the heating zones in the plasticizing unit set to $110,120,130$ and $140{ }^{\circ} \mathrm{C}$, respectively, while the temperature of the head in the heating zones was set to $150{ }^{\circ} \mathrm{C}$. In extrusion with the above blowing agents it is essential that the decomposition temperature of the blowing agent be exceeded at adequate processing conditions. In cellular extrusion, the temperature of the extruder head should be similar to the decomposition temperature of the blowing agent. The preset rotational speed of the screw was changed in the range between 0.83 and $1.66 \mathrm{~s}^{-1}(50-100 \mathrm{rpm})$. The temperature of the cooling agent in the cooling device was measured by a temperature sensor and maintained between 16 and $19{ }^{\circ} \mathrm{C}$.

Given the objective and research methodology, we devised a set of parameters to describe the investigated cellular extrusion process. The following parameters were investigated in the experimental tests:

- direct parameters: temperature of the extrudate leaving the extruder head die $\mathrm{t}_{\mathrm{e}}\left({ }^{\circ} \mathrm{C}\right)$, weight of the measuring length of the extrudate $\mathrm{m}_{\mathrm{e}}(\mathrm{kg})$, number of revolutions of the electric energy meter, $\mathrm{n}(\mathrm{rev})$,

- indirect (resulting) parameters: mass flow rate of the polymer (mass efficiency of the extru- sion process) $G(\mathrm{~g} / \mathrm{s})$, volumetric flow rate of the polymer $\mathrm{V}\left(\mathrm{cm}^{3} / \mathrm{s}\right)$, power supplied to the extruder $\mathrm{Q}_{\mathrm{e}}(\mathrm{kW})$, power conveyed by the polymer $\mathrm{Q}_{\mathrm{p}}(\mathrm{kW})$, energy efficiency of the extrusion process $\eta_{\mathrm{e}}(\%)$.

The variable parameters were: decomposition characteristics of the blowing agent: exothermic and endothermic blowing agents described in the paper, content of the blowing agent in the polymer: $0.5,1.0,1.5(\% \mathrm{w} / \mathrm{w})$, number of revolutions of the extruder screw v: 50, 65, 80, 100 (rpm).

The constant factors included: polymer type as Alfavinyl GMF/4-31TR, temperature in individual heating zones of the extruder plasticizing unit and head: 110, 120, 130, 140 and 150 ${ }^{\circ} \mathrm{C}$, respectively, extrusion time: $60 \mathrm{~s}$, other geometrical components of the plasticizing unit and extruder head.

The experimental tests of cellular extrusion involved feeding the tested PVC containing 0.5, $1.0,1.5 \%$ by weight blowing agent into the plasticizing unit according to the described test schedule. During the tests, the following were measured: the electric energy consumption, the temperature of the extrudate on leaving the extruder head die and the weight of the tape produced in the processing. After the measurements, the rotational speed of the screw was increased and once the process became stable, we measured the energy, temperature and weight of the produced tape applying another rotational speed of the screw. Following the above pattern, we measured the direct parameters of the polymer using three chemical blowing agents with different decomposition properties. The indirect parameters were investigated using generally know dependencies taken from the literature $[1,11]$. 


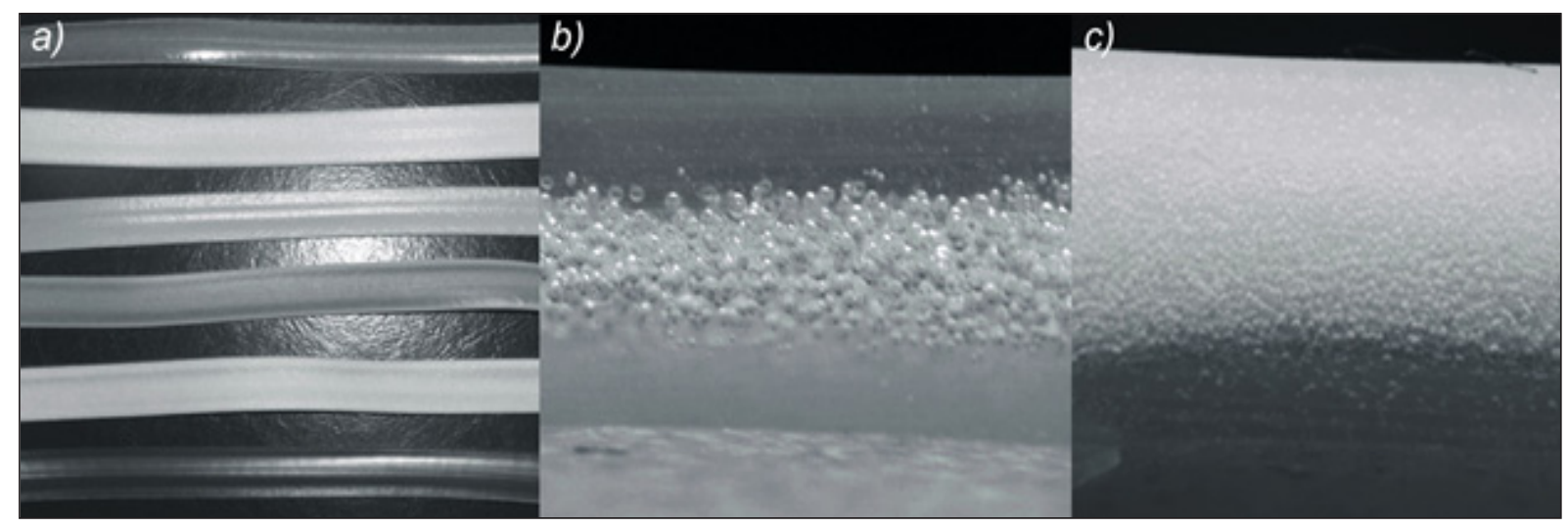

Fig. 2. Fragments of the PVC tapes: (a) view of the solid tape and the cellular tapes, (b) the cross section of the cellular tapes from PVC $+0.5 \%$ LyCell-F017, (c) the cross section of the cellular tapes from PVC $+1.5 \%$ Hydrocerol 530, magnification $13 \times$

\section{RESULTS}

The blowing agent was dosed in $0.5-1.5 \%$ by weight, so as to produce extrudate (tape) with a solid surface and a cellular core (Figure 2). The shape and outside dimensions of the product agree with shape and dimensions of solid products made of the tested PVC. The photographs of the cross section of the tape were taken on the stand for image analysis of cellular plastics that consisted of the Nikon Eclipse LV100ND metallographic microscope equipped with a digital camera, the DS - U3 sensor and a personal computer with suitable software.

Based on the experimental results of poly(vinyl chloride) cellular extrusion, we could determine the relationships between the mass and volumetric flow rates of the polymer, the power supplied to the extruder and conveyed by the polymer as well as the energy efficiency of extrusion and the type and content of the blowing agents and rotational speed of the extruder screw. Generally, the results were the same or similar to a great extent. The results that describe the effectiveness of cellular extrusion are given in Table 1 and Figures 3 through 5.

It was found that the blowing agents (specifically, their type and decomposition characteristics) have an effect on the temperature of extruded material. When the exothermic blowing agent (Hydrocerol 530) is used, the extrudate leaving the extruder head has a temperature that is higher by even $25^{\circ} \mathrm{C}$. This results from the fact that additional heat is released during chemical decomposition of this blowing agent. For this reason, extruded products processed with this particular blowing agents must be subjected to cool- ing. With endothermic blowing agents (Expancel 950MB 80, LyCell-F017), the gas release continues as long as energy is supplied to the extruder. The temperature of the produced extrudate is also higher, but only by $10-16^{\circ} \mathrm{C}$. We did not observe any relationship between the type of the blowing agent applied (endothermic or exothermic) and the energy consumption determined on the basis of the number of revolutions shown by the electricity meter. Nevertheless, a twofold increase in the rotational speed of the screw increased the energy consumption of the process by approx. $12 \%$, irrespective of the blowing agent applied.

Examining the results of the extrudate weight and the polymer mass flow rate $G$ (Figure 3 ), it can be claimed that the effectiveness of cellular extrusion increases with increasing the rotational speed of the screw. This increase is, however, dependent on the blowing agent applied and its content. On the average, the blowing agent in microspheres increased the process output by $25 \%$, $16 \%, 14 \%$ for $0.5 \%, 1 \%$ and $1.5 \%$ of this blowing agent, respectively. The addition of the endothermic blowing agent increased the process output by $15 \%, 13 \%$ and $11 \%$ on the average, whereas the addition of the exothermic blowing agent increased the process efficiency, on the average, by $25 \%, 23 \%, 20 \%$. Examining the blowing agent contents versus different rotational speeds of the screw, it was found that the extrusion output showed a gradual increase. In every group of the tested specimens, the highest differences in the extrusion output were observed at low rotational speeds of the screw. At higher screw speeds, the output of the process increased only to a little extent when the concentration of the blowing agent was increased. 
Table 1. Results of power conducted to the extruder $\mathrm{Q}_{\mathrm{e}}$ and power transmitted through the polymer $\mathrm{Q}_{\mathrm{p}}$ depending on the blowing agent used and extruder screw rotational speed $v$

\begin{tabular}{|c|c|c|c|c|c|c|c|c|c|}
\hline \multirow{4}{*}{$\begin{array}{c}\text { Type } \\
\text { of material }\end{array}$} & \multirow{4}{*}{$\begin{array}{l}\text { Content } \\
\text { of blowing } \\
\text { agent } \\
(\%)\end{array}$} & \multicolumn{8}{|c|}{ Screw rotational speed $v(\mathrm{rpm})$} \\
\hline & & 50 & 65 & 80 & 100 & 50 & 65 & 80 & 100 \\
\hline & & \multicolumn{4}{|c|}{$\begin{array}{l}\text { Power conducted } \\
\text { to the extruder } Q_{e}\end{array}$} & \multicolumn{4}{|c|}{$\begin{array}{c}\text { Power conveyed } \\
\text { by the polymer } Q_{p}\end{array}$} \\
\hline & & \multicolumn{4}{|c|}{$(\mathrm{kW})$} & \multicolumn{4}{|c|}{$(\mathrm{kW})$} \\
\hline PVC solid & 0 & 4.25 & 5.48 & 5.22 & 5.55 & 0.91 & 1.30 & 1.59 & 1.97 \\
\hline \multirow{3}{*}{$\begin{array}{c}\text { PVC+ } \\
\text { Expancel } \\
950 \mathrm{MB} 80\end{array}$} & 0.5 & 4.47 & 3.63 & 4.63 & 5.52 & 1.04 & 1.32 & 1.73 & 2.06 \\
\hline & 1.0 & 4.48 & 4.05 & 5.18 & 4.90 & 1.34 & 1.65 & 2.04 & 2.10 \\
\hline & 1.5 & 4.12 & 4.54 & 5.08 & 6.00 & 1.52 & 1.82 & 2.15 & 2.30 \\
\hline \multirow{3}{*}{$\begin{array}{c}\text { PVC + } \\
\text { LyCell-F017 }\end{array}$} & 0.5 & 4.90 & 4.11 & 4.92 & 4.50 & 1.44 & 1.67 & 2.14 & 2.15 \\
\hline & 1.0 & 4.45 & 4.87 & 5.20 & 5.26 & 1.58 & 1.84 & 2.18 & 2.29 \\
\hline & 1.5 & 5.15 & 4.85 & 4.30 & 4.48 & 1.70 & 2.00 & 2.20 & 2.32 \\
\hline \multirow{3}{*}{$\begin{array}{c}\text { PVC + Hydrocerol } \\
530\end{array}$} & 0.5 & 5.46 & 4.68 & 4.80 & 6.10 & 1.10 & 1.38 & 1.65 & 2.13 \\
\hline & 1.0 & 5.42 & 5.27 & 5.20 & 6.14 & 1.13 & 1.31 & 1.66 & 2.03 \\
\hline & 1.5 & 4.04 & 5.30 & 5.82 & 5.98 & 1.23 & 1.52 & 1.66 & 2.15 \\
\hline
\end{tabular}

The results of the amount of energy supplied to the extruder and the polymer in processing, calculated based on the results of the power $\mathrm{Q}_{\mathrm{e}}$ supplied to the extruder and the power Qp conveyed by the polymer, reveal the effect of the variable parameters, i.e. the type and content of the blowing agent and screw rotational speed, on the investigated parameters (Table 1). The increase in the rotational speed of the screw and concentration of the blowing agent led to an increase in the power conveyed by the polymer. The highest increase in power was observed when the endothermic blowing agent was applied. With the increase in the rotational speed of the screw, the polymer-conveyed power increased on the average by $32 \%$ at $0.5 \%, 41 \%$ at $1.0 \%$ and $48 \%$ at $1.5 \%$ content of the blowing agent. The addition of Expancel $950 \mathrm{MB} 80$ led to an increase in the polymer-conveyed power, on the average by $7 \%$ at $0.5 \%, 27 \%$ at $1.0 \%$ and $39 \%$ at $1.5 \%$ by weight, respectively. The lowest in- crease in the power conveyed by the polymer was produced when the exothermic blowing agent was applied. The average increase in power was $9 \%$ at $0.5 \%, 13 \%$ at $1.0 \%$ and $16 \%$ at $1.5 \%$ content of the blowing agent. Examining the concentrations of the blowing agent at individual rotational speeds of the screw, we also observed a gradual increase in the thermal flux conveyed by the cellular polymer. The results of power supplied to the extruder demonstrate that this parameter increases in each tested case whenever the rotational speed of the screw is increased. We did not observe, however, any dependencies between the content and type of the blowing agent and the power supplied to the extruder at various rotational speeds).

The results of the volumetric flow rate of the polymer given in Figure 4 reveal the relationships similar to those between the polymer mass flow rate and the type of the blowing agent versus different rotational speeds of the screw.
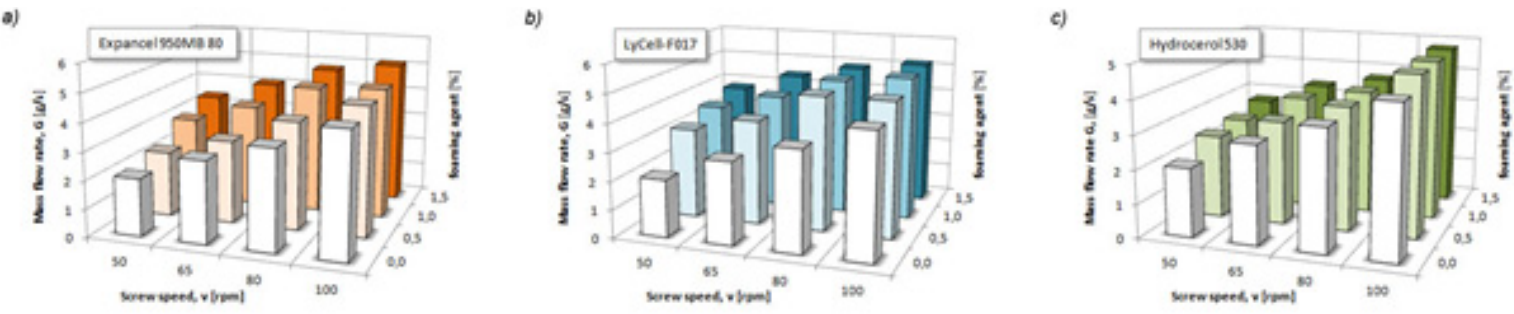

Fig. 3. Dependence of mass flow rate G of cellular PVC with the use of examined endothermic blowing agents in the function of screw rotational speed v: a) Expancel 950MB 80, b) LyCell-F017, c) Hydrocerol 530 
a)

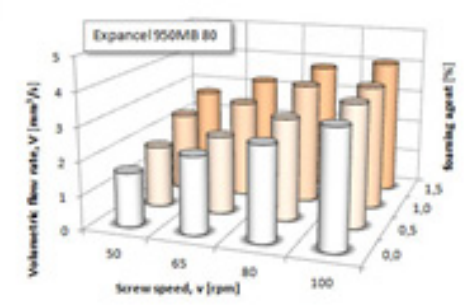

b)

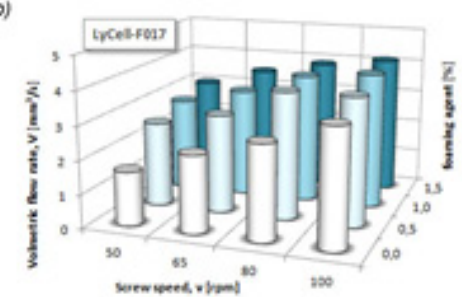

c)

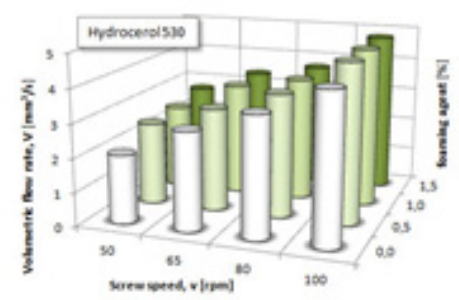

Fig. 4. Dependence of volumetric flow rate $\mathrm{V}$ of the polymer with the use of endothermic blowing agents in the function of screw rotational speed $v$ : a) Expancel 950MB 80, b) LyCell-F017, c) Hydrocerol 530

The measurement of the amount of energy supplied to the extruder and polymer in processing allowed us to determine the energy efficiency of cellular extrusion. The results demonstrate that increasing both the rotational speed of the screw and content of the blowing agents leads to a higher energy efficiency of the process (Figure 5). It was also observed that the endothermic blowing agent has the highest impact on the energy efficiency of cellular extrusion, while the lowest energy efficiency was produced when the exothermic blowing agent was used. The energy efficiency in PVC extrusion with no blowing agent applied was approx. $27.8 \%$. The highest energy efficiency of the process was observed when $1.5 \%$ endothermic blowing agent was applied - on the average, the efficiency was $42.05 \%$. The application of the microsphere-shaped blowing agent yielded the average efficiency of $37.15 \%$, while the lowest efficiency of the extruder was produced when the exothermic blowing agent was used - the average efficiency was $31.53 \%$. The experimental results demonstrate that the increase in energy efficiency is caused by both a higher rotational speed of the screw and the type of the blowing agent applied. However, there is no relationship between the percentage of the blowing agent applied and energy efficiency of the cellular extrusion process.

\section{CONCLUSION}

The experimental results of cellular extrusion demonstrate that the decomposition characteristics of the blowing agent (endothermic or exothermic) and its content in the polymer being processed affect the extrusion process and its effectiveness. It was found that the type of the blowing agent and its content applied in the polymer from 0.5 to $1.5 \%$ by weight had a significant effect on the temperature of the extrudate, the mass and volumetric flows of the polymer and the power transmitted by the polymer, which led to a higher energy efficiency of the extrusion process.

The experimental results partly confirm the observations on extrusion efficiency reported in the works by J.W. Sikora and B. Samujło with regard to the extrusion of non-cellular PVC [11]. The increase in the polymer flow rate due to a higher content of the blowing agent in the polymer mainly results from a lower flow resistance of the PVC being extruded in the flow channels and extruder head die.

Chemical properties of the applied blowing agents facilitate the flow of the polymer through the plasticizing unit and extruder head, which has a direct impact on the output and efficiency of extrusion. This agrees with the observations reported in the studies $[7,12,15]$ respecting to the use of blowing agents with different decomposition
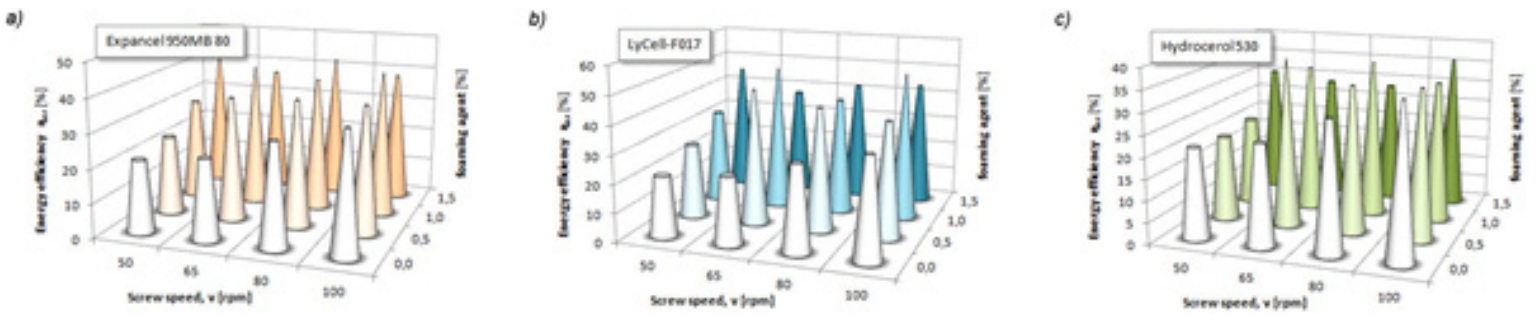

Fig. 5. Dependence of energy efficiency $\eta_{e}$ of the extrusion process with the use of endothermic blowing agents in the function of screw rotational speed $v$ during the extrusion of studied polymers: a) Expancel 950MB 80, b) LyCell-F017, c) Hydrocerol 530 
characteristics in polymer processing and their impact on the polymer being processed.

It was found that the investigated parameters increased the most when the endothermic blowing agent was used, while the application of the exothermic blowing agent led to a lower increase in the above parameters. These relationships are due to characteristics of the blowing agents. The endothermic blowing agent consumes heat during the entire processing. With the parameters set thereby, the extrusion process is the most efficient, which results in improved thermal conduction of the polymer in the plasticizing unit and extruder head and, hence, the highest energy efficiency of the extruder. The exothermic blowing agent produces heat during processing, which leads to the lowest increase in the extrusion output and energy efficiency. We did not observe, however, any noticeable effect of this blowing agent on the magnitude of the power supplied to the extruder. It must be noted, however, that the above observations are reliable only with regard to the blowing agent contents applied in the discussed experiments.

Finally, it was observed that the rotational speed of the extruder screw has a more significant effect on the parameters describing extrusion and its effectiveness than the blowing agent type. The experimental results also confirm that cellular plastics should be processed at high screw speeds, as this will lead to higher polymer flow rate and energy efficiency. What is more, the two parameters can still be increased if a more effective blowing agent is applied and introduced into the polymer.

\section{REFERENCES}

1. Błędzki A. K. And Faruk O. Microcellular Injection Molded Wood Fiber-PP Composites: Part I Effect of Chemical Foaming Agent Content on Cell Morphology and Physico-mechanical Properties. J Cell Plast. 42, 2006, 63-76.

2. Bociagga E. and Palutkiewicz P. The Impact of Mould Temperature and Blowing Agent Content on Structure and Properties of Injection Moulded Parts. Cell Polym. 32, 2013, 257-277.

3. Bociaga E. and Palutkiewicz P. The influence of injection moulding parameters and blowing agent addition on selected properties, surface state and structure of HDPE parts. Polym Eng Sci. 53, 2013, 679-704.

4. Garbacz T. Structure and properties of cellular thin- walled cable coatings. Polimery 57, 2012, 865-868.

5. Jachowicz T., Gajdoš I.: Effect of natural ageing on some properties of oxybiodegrading agent-containing polypropylene products. Przemysl Chemiczny, 93(11), 2014, 1983-1985.

6. Klepka T., Garbacz T., Bociąga E. Some properties of extruded porous microducts. Przemysł Chemiczny 6, 2014, 907-910.

7. Martial S., Jacques F., Audrey C., Clémence N. and Rodier E. New challenges in polymer foaming. A review of extrusion processes assisted by supercritical carbon dioxide. Prog Polym Sci. 36, 2011, 749-766.

8. Prociak A., Sterzyński T., Michałowski S. and Andrzejewski J. Microwave Enhanced Foaming of Carbon Black Filled Polypropylene. Cell Polym. 30, 2011, 201-214.

9. Rachtanapun P., Selke S. E. M. and Matuana L. M. Microcellular foam of polymer blends of HDPE/ PP and their composites with wood fiber. J Appl Polym Sci. 88, 2003, 2842-2850.

10. Rauwendaal Ch. Troubleshooting the Extrusion Process. Munich: Carl Hanser Verlag 2002.

11. Sikora J.W., Samujło B. and Dzwonkowski J. Influence of a feed-opening section on the output and selected mechanical properties of a poly(vinyl chloride) extrudate. J Adv Polym Tech. 33, 2014 (published online) DOI: 10.1002/adv.21388.

12. Tejeda E. H., Sahagún C. Z., González-Núñez R. and Rodrigue D. Morphology and mechanical properties of foamed polyethylene-polypropylene blends. J Cell Plast. 41, 2005, 417-435.

13. Tor-Świątek A., Garbacz T. and Jachowicz T. Quantitative assessment of the microscopic structure of extruded and injected low-density polyethylene modified with microspheres by image analysis. Cellular Polymers, 2(35), 2016, 67-84.

14. Tor-Świątek A. and Samujło B. Use of thermovision research to analyze the thermal stability of microcellular extrusion process of poly(vinyl chloride). Maint Reliab. 15, 2013, 58-61.

15. Urbanczyk L., Alexandre M. and Detrembleur Ch. Extrusion foaming of poly(styrene-co- acrylonitrile)/clay nanocomposites using supercritical $\mathrm{CO}_{2}$. Macromol Mater Eng. 295, 2010, 915-922.

16. White J. L., Potente H. Screw Extrusion. Munich: Carl Hanser Verlag 2003.

17. Xu J. and Kishbaugh L. A. Simple Modeling of the Mechanical Properties with Part Weight Reduction for Microcellular Foam. J Cell Plast. 39, 2003, 29-47.

18. Zhou Q. and Chuan-Bo C. Exo-endothermic blowing agent and its blowing behavior. J Cell Plast. 41, $2005,225-234$. 